\title{
Novel and classical molecular pathways identified in pituitary tumorigenesis using mRNA profiling.
}

\author{
R Formosa ${ }^{1}, \mathrm{~J} \mathrm{Borg}^{3}$, J Vassallo ${ }^{1,2}$
}

Department of Medicine, University of Malta Medical School, Msida, Malta, ${ }^{2}$ Neuroendocrine Clinic, Mater Dei Hospital, Msida, Malta; ${ }^{3}$ Department of Applied Biomedical Sciences, Faculty of Health Science, University of Malta, Msida, Malta.

\section{SCOPE}

To identify novel molecular pathways involved in pituitary tumorigenesis using mRNA expression profiles.

\section{METHODS}

- RNA extracted from 8 pituitary tumours (5 NFPA, 2 GH-secreting tumours, 1 Prolactin/TSH- co-secreting) and pooled normal pituitary control RNA were used for microarray RNA expression analysis on Affymetrix HuGene 1.0 ST Chip.

- Microarray data was analyzed using GeneScript GX 11.0 and network analysis was carries out using the Ingenuity Pathway Analysis (IPA) software.

- Data from microarrays was verified using RNA from 30 pituitary tumours (20 NFPA, 6 GH-secreting, 2 PRL-secreting and $2 \mathrm{ACTH}$-secreting tumours) using quantitative PCR of key genes involved in the networks identified by the IPA.

\section{RESULTS}

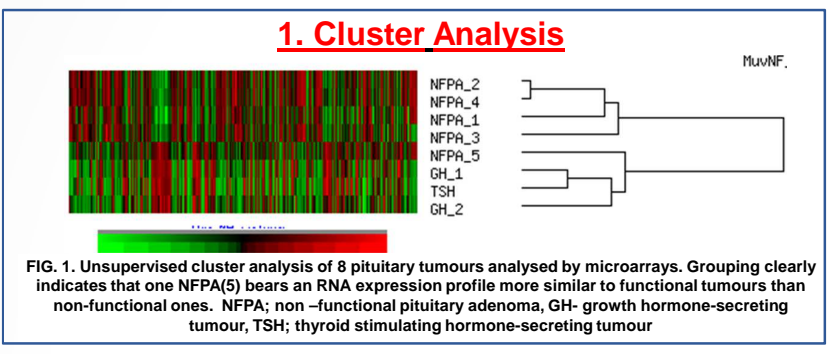

2. Verification by qPCR

Fold Changes of Genes related to Pituitary Developmen

$$
\text { (1) }
$$

Fold Changes of Genes related to Wnt Signalling

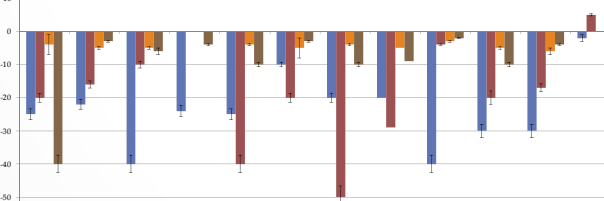

FIG. 2. Fold changes of 8 genes related to pituitary development and Wnt signalling analysed by PCR (q) and Microarray analysis (M). Another 15 genes were used for veritication related to $C A M P$ genes. qPCR results indicate relative quantification normalised with GAPDH and EMC7 housekeeping genes. FPA; functional pituitary adenomas, ACTH; adrenocortico tropic hormone.

\section{CONCLUSTONS}

- Microarrays coupled with qPCR are a useful tool in characterizing tumour types.

- Classical pathways were confirmed by microarray and IPA namely the CAMP signalling, $\mathrm{PI}_{3} \mathrm{~K}$ cascade and Wnt signalling pathways ${ }^{(1,2,3)}$

- Wnt pathway inhibitors are greatly down-regulated, however, canonical signalling through $\beta$-catenin appears unaltered.

- Novel pathway identified include the AHR signalling, GABA receptor signalling and $p 53$ signalling pathways among others.
3. Canonical Pathways involved in Pituitary Adenomas

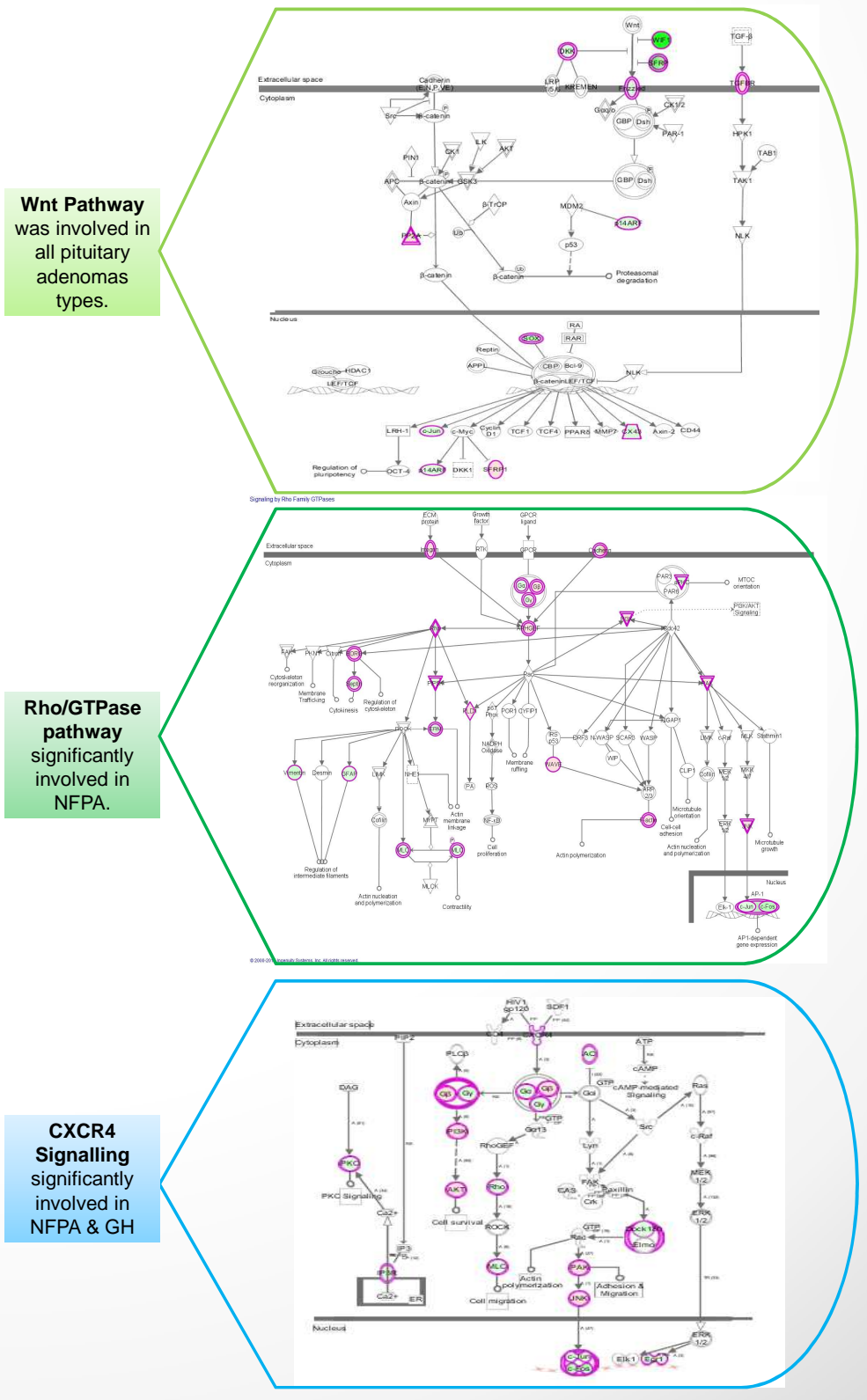

References

A

2 Elston MS, Gill AJ, Conaglen JV, Clarkson A, Shaw JM, Law AJ, Cook RJ, Little NS, Clitton-Bligh RJ, Robinson BG, McDonald KL. 2008. Wnt pathway

Rubinfeld H. Shimon I. 2012. PI3K/AKt/mTOR and Raf/MEK/ERK signalling pathway perturbations in non-functioning pituitary adenomas. Endocrine. 42(2), 